\title{
Accompanying prostate pathologies in patients undergoing radical cystoprostatectomy due to bladder cancer
}

\section{Mesane kanseri nedeniyle radikal sistoprostatektomi yapılan hastalarda eşlik eden prostat patolojileri}

\author{
Cevahir Özer1, Bermal Hasbay2
}

1Başkent Üniversitesi Adana Dr. Turgut Noyan Uygulama Ve Araştırma Merkezi, Üroloji Bölümü, Adana 2Başkent Üniversitesi Adana Dr. Turgut Noyan Uygulama Ve Araştırma Merkezi, Patoloji Bölümü, Adana

\begin{abstract}
ÖZET
GİRIŞ̧ ve AMAÇ: $\mathrm{Bu}$ çalışmada ürotelyal mesane kanseri nedeniyle radikal sistoprostatektomi yapılan hastalarda eşlik eden prostat patolojilerini değerlendirmeyi amaçladık.

YÖNTEM ve GEREÇLER: Retrospektif çalışmada, 2001 - 2019 tarihleri arasında mesane tümörü nedeniyle radikal sistektomi yapılan 197 hasta değerlendirildi. Non-ürotelyal mesane kanseri nedeniyle opere edilenler, kadınlar, prostat korunarak sistektomi yapılanlar ve operasyon öncesinde prostat kanseri tanısı olan hastalar çalışma dişı bırakıldı. Ürotelyal mesane tümörü nedeniyle radikal sistoprostatektomi yapılan toplam 169 erkek hasta çalışmaya dahil edildi.

BULGULAR: Hastaların yaş ortalaması $64.9 \pm 8.2(38$ - 86) yıldı. Eşlik eden prostat patolojilerinin dağılımı 80 $(\% 47.3)$ hastada benign prostat patolojileri, 38 (\%22.5) hastada yüksek dereceli prostatik intraepitelyal neoplazi ve $51(\% 30.2)$ hastada prostat kanseri şeklindeydi. 47 (\%27.81) hastada mesane kanserinin prostata invazyonu mevcuttu. Prostat kanseri saptanan hastaların prostat spesifik antijen değerleri $(3.5 \pm 3.0)$ prostat kanseri olmayanlara göre $(2.6 \pm 4.0)$ anlamlı olarak yüksekti $(\mathrm{p}=0.014)$.

TARTIŞMA ve SONUÇ: Mesane kanseri nedeniyle opere edilecek erkek hastaların yönetiminde prostat kanserinin, prostat kanseri prekürsörü lezyonların ve prostata mesane kanseri invazyonun eşlik edeceği göz önünde bulundurulmalıdır. Prostat koruyucu sistektomi planlanan hastalarda operasyon öncesi prostatın ayrıntılı olarak değerlendirilmelidir. Mesane kanserine eşlik eden prostat kanserinin klinik önemi tartışmalı olsa da, Gleason skoru yüksek ileri yaşı hastaların prostat kanseri açısından takibi göz ardı edilmemelidir.

Anahtar Kelimeler: mesane kanseri, sistoprostatektomi, prostat kanseri
\end{abstract}

\section{ABSTRACT}

INTRODUCTION: In this study, we aimed to evaluate the accompanying prostate pathologies in patients undergoing radical cystoprostatectomy for urothelial bladder cancer.

METHODS: In the retrospective study, 197 patients who underwent radical cystectomy due to bladder tumor between 2001 and 2019 were evaluated. Those who were operated for non-urothelial bladder cancer, women, those who underwent prostate-sparing cystectomy, and those diagnosed with prostate cancer before the operation were excluded. A total of 169 male patients who underwent radical cystoprostatectomy due to urothelial bladder tumor were included in the study.

RESULTS: The mean age of the patients was $64.9 \pm 8.2(38-86)$ years. Distribution of concomitant prostate pathologies was benign prostate pathologies in $80(47.3 \%)$, high grade prostatic intraepithelial neoplasia in 38 $(22.5 \%)$ and prostate cancer in $51(30.2 \%)$ patients. Prostate specific antigen values $(3.5 \pm 3.0)$ of patients with prostate cancer were significantly higher than those without prostate cancer $(2.6 \pm 4.0)(\mathrm{p}=0.014)$.

DISCUSSION AND CONCLUSION: In the management of male patients who will be operated for bladder cancer, it should be considered that prostate cancer, prostate cancer precursor lesions and prostate invasion might accompany bladder cancer. Prostate should be evaluated in detail before the operation in patients who are planned to undergo prostate-sparing cystectomy. Although the clinical importance of prostate cancer accompanying bladder cancer is controversial, the follow-up of patients with advanced Gleason score in terms of prostate cancer should not be ignored.

Keywords: bladder cancer, cystoprostatectomy, prostate cancer

\begin{tabular}{ll}
\hline GíRiş & görülen dokuzuncu kanserdir. Erkeklerde \\
kadınlara göre yaklaşık 3 kat daha sık görülen
\end{tabular}


Orijinal Makale

arasında, prostat kanserinden sonra, ikinci sırada yer almaktadır (1). Primer mesane kanserlerinin \%90-95'i ürotelyal karsinomdur, kalan \%5-10'u ise diğer histolojik tipdeki epitelyal ve/veya mezenkimal tümörler oluşturmaktadır (2). Mesane kanserlerinin yaklaşık \%25'i tanı anında kasa invazedir (3). Kasa invaze ve çok yüksek riskli kasa invaze olmayan mesane kanserlerinin tedavisinde optimal seçenek radikal sistektomidir $(4,5)$. Erkeklerde, standart radikal sistektomi mesane ile birlikte prostat, seminal veziküller ve vaz deferenslerin distal ucu da çıkartılarak radikal sistoprostatektomi şeklinde yapılmalıdır (6). Bu durum, mesane kanserine eşlik eden prostat patolojilerinin klinik açıdan değerlendirilmesini önemli hale getirmektedir. $\mathrm{Bu}$ patolojilerden en önemlisi, erkeklerde akciğer kanserlerinden sonra en sık görülen kanser olan, prostat kanseridir (1). Bununla birlikte, radikal sistektomi yapılan olgulara eşlik eden prostat kanseri olgularının büyük çoğunluğu organa sınırlı ve klinik olarak önemsizdir $(7,8,9,10)$.

$\begin{array}{ccl}\text { Bu çalışmada, mesane kanseri } & \begin{array}{c}\text { mestomi } \\ \text { nedeniyle }\end{array} \text { radikal } & \text { sistoprostatektomi }\end{array}$ uyguladığımız hastalarımızda eşlik eden prostat patolojilerini güncel literatür eşliğinde değerlendirmeyi amaçladık.

\section{GEREÇ ve YÖNTEM}

$\mathrm{Bu}$ retrospektif çalışmada, 2001 - 2019 tarihleri arasında sistektomi yapılan 197 hasta değerlendirildi. Ürotelyal mesane tümörü nedeniyle radikal sistoprostatektomi yapılan 169 erkek hasta çalışmaya dahil edildi. Nonürotelyal mesane tümörü nedeniyle opere edilen 7 hasta, kadın hastalar (toplam 17 hasta), prostat korunarak sistektomi uygulanan 2 hasta, eozinofilik sistit nedeniyle opere edilen 1 hasta ve öncesinde prostat kanseri tanısı olan 1 hasta çalışma dışı bırakıldı. Tüm hastalardan operasyon öncesi aydınlatıımış onam formu alındı. Tüm hastalara standart açı radikal sistoprostatektomi uygulandı. Cerrahi örnekler \%10'luk formalin ile fikse edildikten sonra mesanede tümörden, ön ve arka duvarda, sağ ve sol domdan, üreter ve lenf nodlarından örnekler alındı. Prostat ise 2-3 mm aralıklarla dilimlenerek, apeks ve seminal veziküller dahil haritalandırılarak örneklendirildi. Parafin bloklanan örnekler 3-5 $\mu \mathrm{m}$ aralığında kesilip, Hematoksilen-Eozin ile boyandıktan sonra değerlendirildi. Mesane tümörü patolojik tümör (pT) evrelemesi için TNM sınıflaması, histopatolojik tiplendirmesi ve derecelendirmesi için ise Dünya Sağıı Örgütü sınıflaması kullanıldı $(11,12)$. Eşlik eden prostat kanseri ise Gleason sistemine göre derecelendirilmiştir (13). Bu çalışma Başkent Üniversitesi Tıp ve Sağlık Bilimleri Araştırma Kurulu tarafından onaylandı (Proje no: KA19/432) ve Başkent Üniversitesi Araştırma Fonu tarafından desteklendi. Yaş, operasyon öncesi prostat spesifik antijen (PSA) düzeyi, mesane kanserlerinin pT evresi, eşlik eden prostat patolojileri (benign prostat patolojileri, yüksek dereceli prostatik intraepitelyal neoplazi [PIN], prostat kanseri), mesane kanserinin prostata invazyonu ve prostat kanseri tespit edilen olgularda patolojik tümör derecesi (Gleason skoru) kaydedildi.

\section{İstatistiksel analiz}

Verilerin istatistiksel analizinde SPSS 23.0 paket programı (SPSS Inc., Chicago, IL, USA) kullanıldı. Kategorik ölçümler sayı ve yüzde olarak, sürekli ölçümlerse ortalama ve standart sapma (gerekli yerlerde ortanca ve minimum - maksimum) olarak özetlendi. Gruplar arasında sürekli ölçümlerin karşılaştırılmasında dağılımlar kontrol edildi, parametrik dağılım gösteren değişkenler için Tek Yönlü Varyans Analizi ve ya Student T test, parametrik dağılım göstermeyen değişkenler için Mann Whitney U ve ya Kruskall Wallis testi kullanıldı. Tüm testlerde istatistiksel önem düzeyi 0.05 olarak alındı.

\section{BULGULAR}

Hastaların yaş ortalaması $64.9 \pm 8.2(38-86)$ yıldı. Eşlik eden prostat patolojilerinin dağılımı 80 (\%47.3) hastada benign prostat patolojileri (benign prostat hiperplazisi, granülomatöz prostatit gibi), 38 (\%22.5) hastada yüksek dereceli PIN ve 51 (\%30.2) hastada prostat kanseri şeklindeydi. 47 (\%27.8) hastada mesane kanserinin prostata stromal invazyonu 


\section{Orijinal Makale}

mevcuttu. Invazyon görülen hastalarda, 33 (\%19.5) hastaya benign prostat patolojileri, 9 (\%5.3) hastaya prostat kanseri ve 5 (\%3.0) hastaya ise yüksek dereceli PIN eşlik ediyordu. 47 (\%27.8) hastada sadece benign prostat patolojileri mevcuttu. Hastaların ortalama PSA değeri $2.8 \pm 3.7(0.14-29.91) \mathrm{ng} / \mathrm{mL}$ idi. Prostat kanseri saptanan hastaların PSA değerleri $(3.5 \pm 3.1,0.30-12.97)$ hem prostat kanseri olmayanlara göre $(2.6 \pm 4.0,0.14-$ 29.91) hem de yüksek dereceli PIN ( $2.4 \pm 3.0$, $0.17-10.62$ ) ve diğer (benign patolojiler ve izole invazyon) $(2.6 \pm 4.4,0.14-29.91)$ gruplarına göre anlamlı olarak yüksekti $(p=$ 0.014) (Resim 1). Bununla birlikte, hasta sayısının az olması nedeniyle, prostat kanseri tespiti için PSA eşik değeri belirlenemedi. Hastaların klinik ve patolojik özellikleri Tablo 1'de özetlenmiştir.

Prostat kanseri tespit edilen hastaların sonuçları değerlendirildiğinde, sadece 1 hastada Gleason skoru >7 (Grade grup 5) iken, 3 hastada Gleason skoru 7 (Grade grup 2), kalan 47 hastada ise Gleason skoru $<7$ (Grade grup 1) idi. Ürotelyal karsinomun prostata invazyonu 4 hasta mukozal, 43 hastada ise stromal invazyon şeklindeydi. Mukozal invazyon görülen hastalardan 2 tanesinin mesane tümörü pT evresi 0,1 tanesin 1, kalan 1 tanesinin ise 3 idi. Stromal invazyon görülen olguların tamamı evre 4 idi.

Tablo 1. Hastaların klinik ve patolojik özellikleri.

\begin{tabular}{|c|c|c|c|c|c|}
\hline & $\mathrm{PCa}$ & HG-PIN & Diğer & Toplam & $\mathrm{p}$ \\
\hline $\mathrm{n}(\%)$ & $51(30.2)$ & $38(22.5)$ & $80(47.3)$ & 169 (100) & - \\
\hline Yaş (yıl) & $\begin{array}{l}62.9 \pm 8.4 \quad(45- \\
86)\end{array}$ & $64.8 \pm 7.7(44-85)$ & $66.4 \pm 8.4(38-86)$ & $\begin{array}{l}64.9 \pm 8.2 \\
86)\end{array}$ & 0.140 \\
\hline Mesane T evresi, n (\%) & & & & & 0.065 \\
\hline T0 & $3(1.8)$ & $6(3.6)$ & $5(3)$ & $14(8.3)$ & \\
\hline Tis & $3(1.8)$ & $3(1.8)$ & $2(1.2)$ & $8(4.7)$ & \\
\hline $\mathrm{T} 1$ & $3(1.8)$ & $7(4.1)$ & $7(4.1)$ & $17(10.1)$ & \\
\hline $\mathrm{T} 2$ & $16(9.5)$ & $11(6.5)$ & $18(10.5)$ & $45(26.6)$ & \\
\hline T3 & $12(7.1)$ & $7(4.1)$ & $15(8.9)$ & $34(21.1)$ & \\
\hline $\mathrm{T} 4$ & $14(8.3)$ & $4(2.4)$ & $33(19.5)$ & $51(30.2)$ & \\
\hline Prostat invazyonu, n (\%) & $9(17.6)$ & $5(13.2)$ & $33(41.3)$ & $47(27.8)$ & 0.001 \\
\hline PSA (ng/mL) & $\begin{array}{l}3.5 \pm 3.1 \quad(0.30- \\
12.97)\end{array}$ & $\begin{array}{l}2.4 \pm 3.0 \\
10.62)\end{array}$ & $\begin{array}{l}2.6 \pm 4.4 \quad(0.14- \\
29.91)\end{array}$ & $\begin{array}{l}2.8 \pm 3.7 \\
29.91)\end{array}$ & 0.014 \\
\hline
\end{tabular}




\begin{tabular}{|c|c|c|c|}
\hline Gleason skoru, n (\%) & & - & - \\
\hline$<7$ & $47(92.2)$ & & \\
\hline 7 & $3(5.8)$ & & \\
\hline$>7$ & $1(2.0)$ & & \\
\hline
\end{tabular}

n: sayı, PCa: prostat kanseri, HGPIN: yüksek dereceli prostatik intraepitelyal neoplazi, T: tümör, is: in-situ

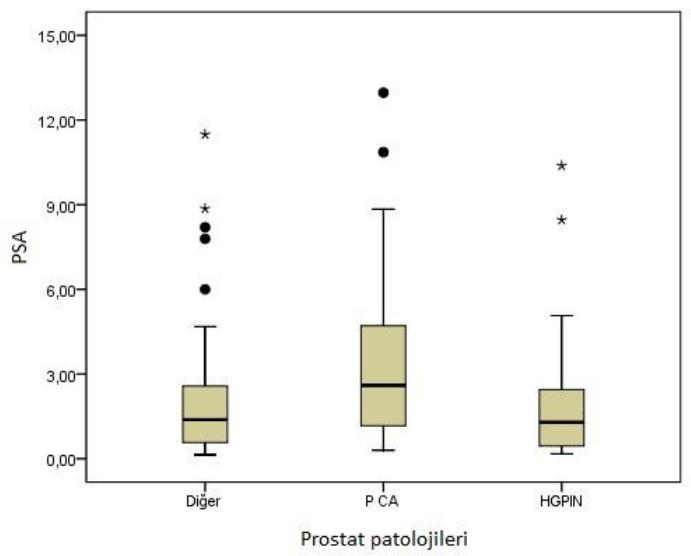

Resim 1. Farklı prostat patolojilerindeki PSA düzeyleri.

\section{TARTIŞMA}

Invaziv mesane kanseri olan hastalardan elde edilen sistoprostatektomi örneklerinin dikkatli bir patolojik değerlendirmesi, eşlik eden prostat lezyonlarının sıkığını değerlendirmek için mükemmel bir fırsat sağlar (14). Ayrıca, mesane kanserli erkek hastaların ameliyat öncesi ve sonrası dönemdeki yönetimine önemli katkıda bulunur.

Literatürde,

radikal sistoprostatektomi uygulanan hastalarda eş zamanlı prostat kanseri sıklığı \%10 ile \%60 arasında bildirilmektedir (15). Oranlar arasında bu değişkenlik çalışmalardaki epidemiyolojik, hastaların etnik kökenleri ve patolojik örnekleme tekniklerindeki farklılıklar ile açıklanabilir $(7,16-18)$. Batı ülkelerinde bu oran yaklaşık \%28'dir (19). Ülkemizden bildirilen yayınlara baktığımızda ise bu oranın \%9 ile \%22.6 arasında değiştiğini görmekteyiz (20- 27). Bizim çalışmamızda ise 51 hastada (\%30.2) prostat kanseri tespit edilmiştir. Bu oran Batı ülkeleri için bildirilen oran ile uyumlu iken ülkemizden bildirilen oranların üzerindedir. Bu farklılığı hastaların ikamet yerlerindeki farklılıkla açıklamak mümkün görünmemektedir (28). Bununla birlikte, bu durumun patolojik değerlendirme farklılıklarından kaynaklanabileceği göz önünde bulundurulmalıdır. Prostat kesitlerinin kalınlığı ve prostatın tamamının ya da bir kısmının örneklenmesi oranlar arasındaki farklılığa neden olabilir (10). Balcı ve ark. (20), ince kesit aralıkları ile her kadrandan örnekleme yaptıklarını belirtirken, Hızlı ve ark. (24) ile Türk ve ark. (22) ise $3 \mathrm{~mm}$ kalınlıkta kesitlerle örnekleme yapmışlardır. Hızlı ve ark. kesit aralığı bilgisi vermez iken Türk ve ark. her kadrandan örnekleme yaptıklarını belirtmişlerdir. Selimoğlu ve ark. (27) çalışmasında kesit aralığı bilgisi verilmeden, her kadrandan örnekleme yapıldığı vurgulanmıştır. Sonuçlarımızı karşılaştırdığımız diğer çalışmalarda ise patolojik değerlendirme ile kesit ve kadran bilgisi verilmemiştir $(21,23,25,26)$. Bizim çalışmamızda ise prostat dokusu 2-3 $\mathrm{mm}$ aralıklarla ve haritalama ile 


\section{Orijinal Makale}

değerlendirilmiştir. PSA düzeyi yüksek olan olguların preoperatif prostat biyopsisi ile değerlendirilmeden çalışmaya dahil edilmesi yalancı rastlantısal prostat kanserine neden olabileceği göz önünde bulundurulmalıdır. Ülkemizden bildirilen yayınlara baktığımızda, sadece Turan ve ark. peroperatif prostat kanseri şüphesi olan olguları çalışma dışında bırakmışlardır ve rastlantısal prostat kanseri oranlarını \%22.6 olarak bildirmişlerdir (23). Fahmy ve ark. tarafından yapılan ve 13140 hastanın değerlendirildiği ve prostat kanseri şüphesi olan olguların da çalışmaya dahil edildiği sistematik derleme ve meta-analizde rastlantısal prostat kanseri oranı \%22.4 olarak bildirilmiştir ve şüpheli olgularda preoperatif prostat biyopsisinin sinir koruyucu ya da prostat koruyucu cerrahi planlanan hastalar dışında klinik katkısının düşük olduğu vurgulanmıştır (18).

Radikal sistoprostatektomilere eşlik edebilen bir diğer prostat patolojisi olan yüksek dereceli PIN, prostat adenokarsinomlarının öncü lezyonları olarak kabul edilirler (29). Prostat iğne biyopsilerinin yaklaşık \%5'inde ve radikal prostatektomi materyallerinin hemen tamanında görülürler. İğne biyopsisinde görülen yüksek dereceli PIN, prostat biyopsisi tekrarında karsinom bulma oranının \%25 olduğunu gösterir (30). Literatürde radikal sistoprostatektomi yapılan olgularda izole yüksek dereceli PIN görülme oranı $14 \%$ ile $\% 75$ arasında değişmektedir $(31,32)$. Ülkemizden bildirilen yayınlarda ise bu oran sadece 2 yayında bildirilmiştir ve görülme oranı yaklaşık $\% 10$ dur $(20,24)$. Bizim çalışmamızda 38 hastada $(\% 22.5)$ prostat kanseri olmadan yüksek dereceli PIN mevcuttu. Bu oranın ülkemizden bildirilen en yüksek oran olması dikkat çekicidir.

Radikal sistoprostatektomi serilerinde prostatta ürotelyal kanser görülme sıklığı \%12 ile \%48 arasında bildirilmektedir $(14,33)$. Ülkemizden bildirilen yayınlarda ise bu oran \%11.4 ile \%22.4 arasındadır $(20,21)$. Bizim çalışmamızda bu oran \%27.8 bulunmuştur. Sadece 4 hastamızda mukozal invazyon varken 43 hastamızda (\%25.4) stromal invazyon mevcuttu ve stromal invazyon olgularının tamamı evre pT4 idi. Stromal invazyon varlığı azalmış sağkalım ve artmış lenf nodu metastazı ile ilişkili kötü prognostik bir faktör olarak kabul edilmektedir (5). Toplam 122 (\%72.2) hastada prostat kanseri (42 hasta izole, 9 ürotelyal kanser ile birlikte), yüksek dereceli PIN (33 hasta izole, 5 hasta ürotelyal kanser ile birlikte) ve izole ürotelyal kanserin prostata invazyonu (33 hasta) mevcuttu. Bu sonuçlar ortotopik üriner diversiyonlarda daha iyi kontinans ve erektil fonksiyon elde etmeye yönelik planlanan prostat koruyucu radikal sistektomilerde operasyon öncesi ayrıntılı değerlendirmenin önemini ortaya koymaktadır (34). Prostat koruyucu sistektomi planlanan hasta grubunda operasyon öncesi, PSA değerlerinden bağımsız olarak, transrektal ultrasonografi eşliğinde prostat biyopsisi planlanmalıdır (7). Bu hasta grubunun hazırlık aşamasında multiparametrik manyetik rezonans görüntüleme/ultrasonografi füzyon biyopsinin rutin kullanımı bildirilmemiş olsa da bu yöntemin gelecekte hasta seçim kriterlerini iyileştirebileceği düşünülmektedir (35).

Radikal sistoprostatektomi sırasında rastlantısal tespit edilen prostat kanserlerinin klinik önemi, bu kanserlerin büyük çoğunluğunun iyi diferansiye ve organa sınırlı olması ve sağkalımın temelde mesane kanseri ile ilişkili prognostik parametrelere bağlı olmasından dolayı tartışma konusu olmaya devam etmektedir $(7,8,9,10)$. Bununla birlikte, Gleason skoru 7 ve üzerinde olan 60 yaş üzeri olgularda, özellikle büyük kribriform/intraduktal morfoloji varlığında, eşlik eden prostat kanserinin sağkalımı olumsuz etkileyebileceği bildirilmiştir (10). Çalışmamızın retrospektif ve hasta sayısının nispeten az olması temel dezavantajlarıdır. Her ne kadar, bu çalışma sağkalım analizine yönelik olmasa da, prostat kanserli olgularda kanser hacminin ölçümünün yapılması bize daha fazla bilgi sağlayabilirdi. Prostat kanseri dışındaki prostat patolojilerinin de tartışılması ise çalışmamızın güçlü yanını oluşturmaktadır. Sonuç olarak, radikal sistoprostatektomi yapılan hastaların büyük bölümünde prostat kanseri, yüksek dereceli PIN ve mesane kanserinin prostata invazyonunun eşlik etmesi prostat koruyucu sistektomi planlanan hastalarda operasyon 
öncesi prostatın ayrıntılı olarak

değerlendirilmesinin önemini bir kere daha ortaya koymaktadır. Mesane kanserine eşlik eden prostat kanserinin klinik önemi tartışmalı olsa da, Gleason skoru yüksek ileri yaşlı hastaların prostat kanseri açısından takibi göz ardı edilmemelidir.

\section{REFERANSLAR}

1. Ferlay J, Soerjomataram I, Dikshit R, Eser S, Mathers C, Rebelo M, Parkin DM, Forman D, Bray F. Cancer incidence and mortality worldwide: sources, methods and major patterns in GLOBOCAN 2012. Int J Cancer 2015;136:E359-386.

2. Manunta A, Vincendeau S, Kiriakou G, Lobel B, Guille F. Non-transitional cell bladder carcinomas. BJU Int 2005;95:497-502.

3. Kamat AM, Hahn NM, Efstathiou JA, Lerner SP, Malmstrom PU, Choi W, Guo CC, Lotan Y, Kassouf W. Bladder cancer. Lancet 2016;388:2796-2810.

4. Leow JJ, Bedke J, Chamie K, Collins JW, Daneshmand S, Grivas P, Heidenreich A, Messing EM, Royce TJ, Sankin AI, Schoenberg MP, Shipley WU, Villers A, Efstathiou JA, Bellmunt J, Stenzl A. SIU-ICUD consultation on bladder cancer: treatment of muscle-invasive bladder cancer. World J Urol 2019;37:61-83.

5. Monteiro LL, Witjes JA, Agarwal PK, Anderson CB, Bivalacqua TJ, Bochner BH, Boormans JL, Chang SS, Dominguez-Escrig JL, McKiernan JM, Dinney C, Godoy G, Kulkarni GS, Mariappan P, O'Donnell MA, Rentsch CA, Shah JB, Solsona E, Svatek RS, van der Heijden AG, van Valenberg FJP, Kassouf W. ICUD-SIU International Consultation on Bladder Cancer 2017: management of non-muscle invasive bladder cancer. World J Urol 2019;37:51-60.

6. Chang SS, Bochner BH, Chou R, Dreicer R, Kamat AM, Lerner SP, Lotan Y, Meeks JJ, Michalski JM, Morgan TM, Quale DZ, Rosenberg JE, Zietman AL, Holzbeierlein JM. Treatment of Non-Metastatic Muscle-Invasive Bladder Cancer: AUA/ASCO/ASTRO/SUO Guideline. J Urol 2017;198:552-559.

7. Malte R, Kluth LA, Kaushik D, Boorjian SA, Abufaraj M, Foerster B, Rink M, Gust K, Roghmann F, Noldus J, Vordos D, Hagiwara M, Kikuchi E, Ikeda M, Matsumoto K, Karakiewicz PI, Roupret M, Briganti A, Scherr DS, Shariat SF, Seebacher V. Frequency and prognostic significance of incidental prostate cancer at radical cystectomy: Results from an international retrospective study. Eur J Surg Oncol 2017;43:2193-2199.

8. Damiano R, Di Lorenzo G, Cantiello F, De Sio M, Perdona S, D'Armiento M, Autorino R. Clinicopathologic features of prostate adenocarcinoma incidentally discovered at the time of radical cystectomy: an evidence-based analysis. Eur Urol 2007;52:648-657.

9. Tang S, Hao H, Fang D, Zheng W, Ge P, Su X, He Q, Yang X, Shen Q, Li X, Yu W, Lin J, Zhou L. Prostate cancer incidentally discovered at the time of radical cystoprostatectomy does not decrease overall survival: Results from a large Chinese medical center. Int Braz J Urol 2018;44:258-266.

10. Lopez-Beltran A, Cheng L, Montorsi F, Scarpelli M, Raspollini MR, Montironi R. Concomitant bladder cancer and prostate cancer: challenges and controversies. Nat Rev Urol 2017;14:620-629.

11. Eble JN, World Health O, International Academy of P. Pathology and genetics of tumours of the urinary system and male genital organs. Lyon, IARC Press, 2004.

12. Mostofi FK, Davis CJ, Sesterhenn I. Histological typing of urinary bladder tumours. Berlin; New York, Springer, 1999.

13. Tannenbaum M. Urologic pathology: the prostate. Philadelphia, Pa, Lea \& Febiger, 1977.

14. Saad M, Abdel-Rahim M, Abol-Enein H, Ghoneim MA. Concomitant pathology in the prostate in cystoprostatectomy specimens: a prospective study and review. BJU Int 2008;102:1544-1550.

15. Tanaka T, Koie T, Ohyama C, Hashimoto Y, Imai A, Tobisawa $\mathrm{Y}$, Hatakeyama $\mathrm{S}$, Yamamoto H, Yoneyama T, Horiguchi H, Kodama H, Yoneyama T. Incidental prostate cancer in patients with muscle-invasive bladder cancer who underwent radical cystoprostatectomy. Jpn J Clin Oncol 2017;47:1078-1082.

16. Zhu YP, Ye DW, Yao XD, Zhang SL, Dai B, Zhang HL, Shen YJ, Zhu Y, Shi GH. Prevalence of incidental prostate cancer in patients undergoing radical cystoprostatectomy: data from China and other Asian countries. Asian J Androl 2009;11:104-108.

17. Mazzucchelli R, Barbisan F, Scarpelli M, Lopez-Beltran A, van der Kwast TH, Cheng L, Montironi R. Is incidentally detected prostate cancer in patients undergoing radical cystoprostatectomy clinically significant? Am J Clin Pathol 2009;131:279-283.

18. Fahmy O, Khairul-Asri MG, Schubert T, Renninger M, Stenzl A, Gakis G. Clinicopathological features and prognostic value of incidental prostate adenocarcinoma in radical cysto-prostatectomy specimens: a systematic review and meta-analysis of 13140 patients. $\mathbf{J}$ Urol 2017;197:385-390.

19. Kurahashi T, Miyake H, Furukawa J, Kumano M, Takenaka A, Fujisawa M. Characterization of prostate cancer incidentally detected in radical cystoprostatectomy specimens from Japanese men with bladder cancer. Int Urol Nephrol 2010;42:73-79.

20. Balci MBC OO, Hazar AI, Ozkan A, Cilesiz NC, Arslan B, Nuhoglu B. Incidental Prostate Cancer Frequency and Features of Patients Undergoing Radical Cystoprostatectomy. JAREM 2016;6:15-18. 


\section{Orijinal Makale}

21. Sari A EM, Calli A, Girgin C. Overview of Histopathologic Features in 191 Radical Cystectomy Specimens with Urothelial Carcinoma. Journal of Inonu University Medical Faculty 2007;14:75-80.

22. Turk H KM, Un S, Tarhan H, Yalbuzdag ON, Bayol NU, Suelozgen T, Isoglu CS, Zorlu F. Incidence and clinical importance of prostate cancer in patients who underwent radical cystoprostatectomy. Ege Journal of Medicine 2015;54:65-69.

23. Turan T DY, Sendogan F, Atis RG, Caskurlu $T$, Yildirim A. The frequency of the incidental prostate cancer of the patients that were diagnosed as bladder cancer and underwent radical cystectomy and the oncological outcomes. The New Journal of Urology 2018;13:16-21.

24. Hizli F AA, Basay S, Benzer E, Uygur MC. The Rate Of Incidental Prostate Cancer in Patients Undergoing Radical Cystoprostatectomy For Bladder Cancer. Turk J Urol 2005;31:490-494.

25. Ceylan Y SV, Polat S, Gunlusoy B, Degirmenci T, Topcu YK, Bolat D, Kozacioglu $\mathrm{Z}$. The Incidence of Prostate Adenocarcinoma in Patients Who Underwent Cystoprostatectomy for Invasive Baldder Cancer and Histopathological Examination. Bulletin of Urooncology 2016;15:61-64.

26. Ugurlu O OV, Kosan M, Doluoglu OG, Adsan $\mathrm{O}$, Cetinkaya M. The Impact of Co-Existing Prostate Adenocarcinoma with Bladder Carcinoma on Disease Specific Survival of the Patients in Our Radical Cystoprostatectomy Series. JCAM 2010;1:1-4.

27. Selimoglu A TA, Hamarat MB, Saglam E, Aslan H, Tarhan F. The Frequency of Incidentally-Detected Prostate Cancer in Patients Undergoing Radical
Cystoprostatectomy for Urotelial Bladder Carcinoma. J Kartal TR 2014;25:53-57.

28. Zorlu F, Zorlu R, Divrik RT, Eser S, Yorukoglu K. Prostate cancer incidence in Turkey: an epidemiological study. Asian Pac J Cancer Prev 2014;15:9125-9130.

29. Bostwick DG, Cheng L. Precursors of prostate cancer. Histopathology 2012;60:4-27.

30. Zhou M. High-grade prostatic intraepithelial neoplasia, PIN-like carcinoma, ductal carcinoma, and intraductal carcinoma of the prostate. Mod Pathol 2018;31:S71-79.

31. Wiley EL, Davidson P, McIntire DD, Sagalowsky AI. Risk of concurrent prostate cancer in cystoprostatectomy specimens is related to volume of high-grade prostatic intraepithelial neoplasia. Urology 1997;49:692696.

32. Han KS, Jeong IG, Joung JY, Yang SO, Chung J, Seo HK, Park WS, Lee KH. Prevalence of high-grade prostatic intraepithelial neoplasia in prostate gland of Korean men: comparisons between radical prostatectomy and cystoprostatectomy. Urology 2007;70:11001103.

33. Abbas F, Biyabani SR, Pervez S. Incidental prostate cancer: the importance of complete prostatic removal at cystoprostatectomy for bladder cancer. Urol Int 2000;64:52-54.

34. Vallancien G, Abou El Fettouh H, Cathelineau X, Baumert H, Fromont G, Guillonneau B. Cystectomy with prostate sparing for bladder cancer in 100 patients: 10-year experience. J Urol 2002;168:2413-2417.

35. Avulova S, Chang SS. Role and Indications of Organ-Sparing "Radical" Cystectomy: The Importance of Careful Patient Selection and Counseling. Urol Clin North Am 2018;45:199214. 